\title{
LAÇOS SOCIAIS
}

\section{Representações do Associativismo entre as mutuais de trabalhadores na Corte do Império*}

\author{
Representations of associativism between workers \\ mutual societies in the Court of the Empire \\ Representaciones del asociativismo entre las mutuales \\ de trabajadores en la Corte del Imperio
}

Mateus Fernandes de Oliveira Almeida**

\begin{abstract}
Resumo: O presente artigo lança luz sobre a cultura associativa entre trabalhadores na Corte do Segundo Reinado através de estatutos de sociedades de mútua ajuda e pareceres emitidos pelos conselheiros de Estado da Seção dos Negócios do Império. Toma particularidade aqui, abordagens que remetem às representações identitárias e os significados de moralidade, altruísmo e nobilitação do trabalho no interior das redes de sociabilidade e da importância a elas creditadas pelos sujeitos históricos em evidência.
\end{abstract}

Palavras-chave: mutualismo; trabalhadores; Corte do Império.

Abstract: This paper sheds light on the culture of partnership between workers of the Court of the Second Empire through mutual aid statutes and opinions issued by State counselors of the Empire Affairs Section. This article also deals with approaches that lead to identity representations and meanings of morality, altruism and ennoblement of work within the social networks and the importance credited to them by historical subjects in evidence.

Keywords: mutualism; workers; imperial court.

\footnotetext{
*Este trabalho é um resultado do financiamento da Fundação de Amparo à Pesquisa do Estado de São Paulo (FAPESP).

**Doutor em História pela Pontifícia Universidade Católica de São Paulo (PUC-SP) com apoio da Fundação de Amparo à Pesquisa do Estado de São Paulo (FAPESP). Investigador Estrangeiro da Rede REMESSAS - Emigração Europa do Sul/América do Sul ligada ao Centro de Estudos da População, Economia e Sociedade da Universidade do Porto (CEPESE/UP). Professor da Faculdade Redentor e da Secretaria de Educação de Minas Gerais. <mathist@ig.com.br>.
} 
Resumen: Este artículo arroja luz sobre la cultura asociativa entre los trabajadores de la Corte del Segundo Imperio a través de estatutos de ayuda mutua y pareceres emitidos por consejeros de Estado de la Sección de Asuntos del Imperio. Toma particularidad aquí los enfoques que llevan a las representaciones de identidad y los significados de la moralidad, el altruismo y el ennoblecimiento del trabajo dentro de las redes de sociabilidad y de la importancia asignada a ellas por sujetos históricos en evidencia.

Palabras clave: mutualismo; trabajadores; corte imperial.

Esta associação tem por fim promover o gosto $e$ o amor ao trabalho em proveito do País, e progresso das artes, e reputação dos artistas brasileiros.

(Estatutos da Associação Nacional dos Artistas Brasileiros Trabalho, União e Moralidade)

O processo de construção da identidade classista e da cultura política entre os trabalhadores, no percurso de suas organizações coletivas, compõe um campo privilegiado da história do trabalho. Tendo em vista a temática, já consideravelmente percorrida pela historiografia ${ }^{1}$, este artigo apoia-se na literatura sobre o tema e toma como base documental, pedidos de consulta a estatutos enviados à Seção dos Negócios do Império do Conselho de Estado pelas sociedades de mútua ajuda de ofícios ou categorias profissionais entre 1860 e 1882.

Nesse espectro, as interações promovidas entre o poder público e os grupamentos civis das classes laboriosas fornecem elementos relacionados às dinâmicas e estratégias associativas, às culturas identitárias, à disposição e pluralização do espaço público, à moralidade do trabalhador, sua formação técnica e intelectual, à nobilitação do trabalho, à proteção contra as inseguranças sociais e à concorrência no mercado de trabalho. A formação de uma aristocracia entre os trabalhadores, as práticas de exclusão societária e a qualificação técnica e intelectual proporcionada pela instrução também são passíveis de discussão com base na documentação produzida pelo

\footnotetext{
1 Desde a década de 1990 uma vasta literatura sobre o tema do mutualismo vem se constituindo. Especificamente sobre mutuais de trabalhadores ou por ofícios merecem destaque: Cadernos AEL (1999); Fortes (1999); Lacerda (2011); Batalha (1992; 1999; 2004); Mac Cord (2009); Nomelini (2007); Silva Jr. (2004), entre outros. Recentemente um amplo repertório sobre o mutualismo foi publicado dedicando especial atenção às experiências mutualistas dos trabalhadores no século XIX e XX (Mac Cord; Batalha, 2014).
} 
governo ${ }^{2}$. Por essa lógica, é possível tecer interpretações acerca das práticas características de uma cultura classista ou laboral, e de outras ainda que não se diferenciam dos traços comuns dos demais tipos de sociabilidade inscritos naquele mesmo contexto histórico.

A proposta, portanto, não consiste em traçar uma análise sistematizada sobre a cultura de classe dos trabalhadores dentro das sociedades de auxílio mútuo, tal como a própria condição das mutuais na formação da classe operária, mas sim extrair das fontes elencadas entendimentos a respeito das práticas e ações dos trabalhadores no campo associativo, dialogando com a literatura sobre as linguagens e identidades forjadas em seu interior, a construção de valores morais, o significado da proteção social e a forma como se relacionavam com o poder público e este concebia os trabalhadores e suas formas coletivas de organização.

\section{Civilizar e moralizar para proteger}

Segundo Silva Jr. (2004), as sociedades de ofícios surgiam como entidades "protetoras" e "auxiliadoras" dos interesses de seus sócios, para dar assistência àqueles que porventura clamassem por ela, ou ainda cumprir com outra função ainda mais importante que proteger: a de proporcionar o sentimento de proteção, atendendo ao seu objetivo primordial de segurança, ou seguridade. Esse diferencial semântico, proteger ou sentir-se protegido, compunha um dos elementos centrais das sociedades de ajuda mútua e/ou beneficentes relacionadas diretamente à sua ação objetiva, à sua finalidade básica: remediar as inseguranças materiais e físicas de seus associados, sobrepor-se às calamidades que entregavam esses sujeitos históricos ao "estado de pobreza" e de se apresentarem como redes de solidariedade voltadas ao combate dos riscos sociais.

Dentro da dinâmica associativa, conforme ilustra a quadro abaixo, as mutuais por ofício ou categoria profissional contabilizaram um

\footnotetext{
2 Trata-se de pareceres emitidos pelo governo imperial, especificamente a $2^{\text {a }}$ Secretaria do Ministério dos Negócios do Império e da Seção dos Negócios do Império do Conselho de Estado, sobre pedidos de sociedades civis requerendo autorização das autoridades públicas para funcionar ou manter suas atividades legalmente. Em 1860 o governo imperial promulgou a Lei 1.083 de 22 de agosto, seguida do Decreto 2.711 de 19 de dezembro, que condicionou quaisquer tipos de sociedades civis a requerer das autoridades competentes em cada província e na capital um pedido de consulta aos seus estatutos para obter reconhecimento jurídico e legal. Na Corte, o órgão responsável por emitir os pareceres anuindo ou não o funcionamento das sociedades foi a Seção dos Negócios do Império do Conselho de Estado, composto por três membros. A Lei e o Decreto foram revogados em 1882.
} 
número significativo de associações no Rio de Janeiro, cuja finalidade voltava-se, em muitos casos, para questões além daquelas atribuídas ao seu caráter imediato: a proteção e seguridade social. Almejavam também a valorização das artes, das identidades laborais, da moralidade e do altruísmo. Desempenharam, portanto, um papel relevante na configuração das redes de sociabilidade no espaço público carioca no percurso dos oitocentos e no estreitamento de laços de solidariedade forjados no interior de sociedades destinadas à mútua ajuda.

Quadro 1. Sociedades de mútua ajuda por ofício ou categoria profissional no Rio de Janeiro (1834-1880)

\begin{tabular}{|l|c|l|}
\hline Nome & Fundação & \multicolumn{1}{|c|}{ Categoria/Ofício } \\
\hline Sociedade Musical de Beneficência & 1834 & Músicos \\
\hline $\begin{array}{l}\text { Imperial Sociedade Auxiliadora das Artes } \\
\text { Mecânicas Liberais e Beneficente }\end{array}$ & 1835 & Diversos ofícios e artes \\
\hline Imperial Associação Tipográfica Fluminense & 1853 & Tipógrafos \\
\hline $\begin{array}{l}\text { Sociedade Beneficente dos Artistas do Arsenal da } \\
\text { Marinha da Corte }\end{array}$ & 1856 & Construção naval \\
\hline Sociedade dos Seculares Empregados da Igreja & 1857 & Diversos ofícios \\
\hline $\begin{array}{l}\text { Sociedade Beneficente dos Artistas da Construção } \\
\text { Naval }\end{array}$ & 1858 & $\begin{array}{l}\text { Artífices da construção } \\
\text { naval }\end{array}$ \\
\hline Sociedade Filantrópica dos Artistas & 1858 & Artes cênicas \\
\hline $\begin{array}{l}\text { Associação Beneficente Artes, Comércio e } \\
\text { Indústria }\end{array}$ & 1860 & Diversos ofícios \\
\hline $\begin{array}{l}\text { Caixa Auxiliadora das Corporações das } \\
\text { Composições Dramáticas e Musicais }\end{array}$ & 1860 & Artes cênicas e músicos \\
\hline $\begin{array}{l}\text { Associação de Socorros Mútuos e Montepio dos } \\
\text { Empregados da Estrada de Ferro D. Pedro II }\end{array}$ & 1861 & Transporte \\
\hline Sociedade Animadora da Corporação dos Ourives & 1838 & Ornamentação \\
\hline $\begin{array}{l}\text { Associação Nacional dos Artistas Brasileiros } \\
\text { Trabalho, União e Moralidade }\end{array}$ & 1852 & Diversos ofícios \\
\hline $\begin{array}{l}\text { Sociedade dos Socorros Mútuos Comércio } \\
\text { União Beneficente Comércio e Artes }\end{array}$ & 1861 & $\begin{array}{l}\text { Guarda-livros, empregados } \\
\text { empregadores do comércio }\end{array}$ \\
\hline $\begin{array}{l}\text { Associação dos Compositores do Jornal do } \\
\text { Comércio }\end{array}$ & 1868 & Tomércio \\
\hline $\begin{array}{l}\text { Sociedade Beneficente Protetora dos Chapeleiros } \\
\text { do Rio de Janeiro }\end{array}$ & 1869 & Chapeleiros \\
\hline Associação Beneficente dos Guarda-Livros & 1869 & Comércio \\
\hline Montepio dos Artistas da Corte & 1870 & Diversos ofícios \\
\hline Liga Operária & Diversos ofícios \\
\hline
\end{tabular}


Quadro 1 (conclusão)

\begin{tabular}{|c|c|c|}
\hline Nome & Fundação & Categoria/Ofício \\
\hline $\begin{array}{l}\text { Associação Cooperadora dos Empregados da } \\
\text { Tipografia Nacional }\end{array}$ & 1873 & Tipógrafos \\
\hline Sociedade Beneficente dos Maquinistas & 1873 & Transporte \\
\hline Sociedade Protetora dos Barbeiros e Cabelereiros & 1869 & Barbeiros e cabelereiros \\
\hline $\begin{array}{l}\text { Sociedade Beneficente } 31 \text { de Outubro Amor ao } \\
\text { Trabalho }\end{array}$ & 1874 & Vários ofícios \\
\hline $\begin{array}{l}\text { Sociedade Beneficente dos Marceneiros, } \\
\text { Carpinteiros e Artes Correlativas no Rio de Janeiro }\end{array}$ & 1875 & Carpinteiros e marceneiros \\
\hline $\begin{array}{l}\text { Sociedade Beneficente dos Artistas de São } \\
\text { Cristóvão }\end{array}$ & 1870 & Diversos ofícios \\
\hline Sociedade dos Artistas Alfaiates & 1876 & Alfaiates \\
\hline Sociedade Montepio Artístico Familiar & 1876 & Diversos ofícios \\
\hline $\begin{array}{l}\text { Sociedade de Socorros Mútuos Protetora dos } \\
\text { Artistas Sapateiros e Profissões Correlativas }\end{array}$ & 1875 & Sapateiros \\
\hline Club Beneficente dos Guarda-Livros & 1876 & Comércio \\
\hline Sociedade Protetora dos Artistas Dramáticos & 1877 & Artes cênicas \\
\hline $\begin{array}{l}\text { Associação de Beneficência Socorros Mútuos dos } \\
\text { Despachantes da Alfândega do Rio de Janeiro }\end{array}$ & 1878 & $\begin{array}{l}\text { Despachantes/ funcionários } \\
\text { públicos }\end{array}$ \\
\hline $\begin{array}{l}\text { Associação dos Empregados no Comércio do } \\
\text { Rio de Janeiro }\end{array}$ & 1880 & Comércio \\
\hline $\begin{array}{l}\text { Sociedade Beneficente dos Empregados da Gazeta } \\
\text { de Notícias }\end{array}$ & 1880 & Imprensa \\
\hline $\begin{array}{l}\text { Sociedade Beneficente de Socorros Mútuos dos } \\
\text { Empregados das Capatazias da Alfândega de Corte }\end{array}$ & 1880 & Transporte \\
\hline $\begin{array}{l}\text { Sociedade de Socorros Mútuos e Montepio dos } \\
\text { Maquinistas }\end{array}$ & 1880 & Transporte \\
\hline $\begin{array}{l}\text { Caixa Beneficente da Corporação Docente do } \\
\text { Rio de Janeiro }\end{array}$ & 1881 & Professores \\
\hline Sociedade Beneficente dos Empregados no Fumo & 1881 & Fumo \\
\hline União Beneficente Protetora dos Cocheiros & 1881 & Transporte \\
\hline $\begin{array}{l}\text { Sociedade de Socorros Mútuos União Comercial } \\
\text { dos Varejistas de Secos e Molhados }\end{array}$ & 1881 & Comércio \\
\hline $\begin{array}{l}\text { Grêmio dos Professores Públicos Primários da } \\
\text { Corte }\end{array}$ & 1881 & Professores \\
\hline Corpo Coletivo União Operária & 1880 & Diversos ofícios \\
\hline
\end{tabular}

Fonte: (BRASIL. Fundo da Seção de Negócios do Conselho de Estado, 1860-1882); (BRASIL. Colecção das Leis do Império do Brasil, 1860-1882); (BRASIL. Almanak Administrativo, Mercantil e Industrial do Rio de Janeiro, 1844-1888). Esses dados sofrem variações em pesquisas e levantamentos realizados sobre mutualismo no Rio de Janeiro no contexto em foco, a saber: Fonseca (2008); Jesus (2009); Lacerda (2011). 
As sociedades de trabalhadores, em geral, constituíam alguns tipos básicos: de classes profissionais ou ofícios, de trabalhadores artífices, de funcionários públicos e militares da Guarda Nacional, de ramos da indústria e do comércio, de artistas cênicos e músicos, entre outros. Todas elas conservavam a finalidade precípua do auxílio mútuo, como também da defesa de interesses forjados na afirmação de suas categorias profissionais, alocadas em um ambiente cuja diversidade de sujeitos e grupamentos sociais configurava um campo adequado às representações simbólicas e representações identitárias. Tais construções perpassavam também pelo olhar do outro e pela forma como esse olhar caracterizava esses significados. Assim, os comportamentos, valores e condutas seguiam padrões de uma moralidade pautada na civilidade com vistas à disciplinarização dos corpos, à honestidade das ações, à vida regrada, aos bons costumes, à dedicação e valorização do trabalho manual, do operário e do artesão.

A Associação Nacional dos Artistas Brasileiros Trabalho, União e Moralidade, fundada em 1861, em seus estatutos garantia o compromisso de "unir em uma só e grande família os filhos do trabalho". Para fazer parte dessa "grande família", uma porção de requisitos era solicitada ao candidato: em primeira instância, ocupar-se ou já ter se ocupado em algum ofício ou arte, gozar de "honesta reputação" e ter ao menos 18 anos de idade. A associação propunha a defesa dos interesses dos artistas brasileiros, numa equação com resultados para além das atividades exclusivamente voltadas para os socorros mútuos, incluindo a valorização do trabalhador por meio de seu enaltecimento técnico e intelectual. Prevalecia um espírito de união e proteção, esta propiciada pelas cotas pecuniárias de cada sócio, ao se ampararem mutuamente como "irmãos" e "filhos do trabalho" nas adversidades e calamidades da vida.

O exemplo da sociedade Trabalho, União e Moralidade reforça a tese, atualmente bem endossada por referências na historiografia social do trabalho, da importância das mutuais na afirmação de uma linguagem ou de linguagens identitárias entre os trabalhadores, a partir da segunda metade do século XIX. Dentro desta perspectiva Cláudio Batalha salienta que em um contexto de mudanças progressivas processadas nas relações sociais de produção, os sentidos atribuídos ao trabalho passavam ao mesmo tempo por uma redefinição simbólica: "Esta é uma dimensão central na linguagem das sociedades mutualistas: o esforço de 'nobilitação' do trabalho, que precede a articulação do discurso classista" (1999, p. 64). 
Por outro lado, isso não quer dizer que, por pertencer a certa sociedade de auxílio mútuo e/ou beneficente de trabalhadores ou de categoria profissional, o operário se sentiria ainda mais operário ou o artesão ainda mais artesão que os seus pares não filiados. Porém, essas associações cumpriam o papel de fortalecer os laços de solidariedade, reconhecimento e valorização da profissão, do trabalho e do trabalhador. A capital abrangia um número considerável de associações constituídas em torno de ofícios manuais na segunda metade do século XIX. Resultado da própria diversificação das atividades artesanais e manufatureiras, acrescida ainda da diminuição da presença dos trabalhadores escravos na economia urbana e o crescimento demográfico que afetavam as condições de vida e trabalho da maioria da população carioca.

Nesse movimento, diferentes categorias de artífices e de operários encontravam, nas sociedades de socorros mútuos, uma possibilidade de buscar suporte material e de criar mecanismos de proteção social, articulando valores culturais referenciados na ética do trabalho e na imagem positiva do trabalhador (JESUS; LACERDA, 2010, p. 135).

As adversidades enfrentadas pelos trabalhadores, em grande parte, eram produzidas pela desqualificação do valor do trabalho manual, pela economia escravista, pelas condições de vida e pela concorrência e composição social do mercado de trabalho, dada a participação cada vez mais crescente de trabalhadores imigrantes, sobretudo portugueses, na Corte do Império. Por outro lado, o sentido do trabalho adquiria outros contornos no percurso dos oitocentos, inserido no processo de transformação e crise da economia senhorial escravista, com o crescimento do trabalho livre e assalariado, o crescente ideário de modernização e o adensamento demográfico do espaço urbano. Passava a ser compreendido também como um emblema de bom caráter, moral e dignidade, contra aqueles que se entregavam ao ócio, à prática de atividades condenáveis, como a mendicância, jogatina, capoeira, prostituição e a vagabundagem.

É, portanto, em torno da noção de trabalho que se inicia a distinção entre 'bons cidadãos' e 'classes perigosas' nas sociedades capitalistas. $\mathrm{O}$ trabalho vem impregnado de uma conotação positiva associada àquele que incorpora a ética do trabalho: o 'bom operário', laborioso, poupador, enquadrado numa perspectiva de ascensão social e, sobretudo, ordeiro (BATALHA, 1992, p. 119). 
Além disso, o ofício manual, acompanhado do conhecimento e da habilidade técnica e desempenhado por artistas ou artífices, investia-se de uma posição privilegiada na hierarquia laboral, forjando uma espécie de aristocracia do mundo do trabalho. Todavia, a condição privilegiada não os eximia de sofrer com as iminentes calamidades da vida e seus riscos sociais, que podiam se abater sobre qualquer classe ou grupo social e demandavam a implementação de mecanismos eficazes de proteção social.

Encontravam-se imbricados, portanto, de um lado, concepções e juízos disseminados no tecido social e, de outro, demandas circunstanciais da vida cotidiana, que projetavam os sujeitos históricos rumo à organização coletiva, na busca de soluções para remediar os riscos sociais, sem, contudo, deixar de reproduzir as idiossincrasias causadas pelas diversas identidades associadas ao trabalhador pobre, ao seu ofício, sua condição econômica, sua cor e nacionalidade. Trabalhadores escravos, livres e libertos, nacionais e estrangeiros, compunham, portanto, uma coletividade bastante heterogênea do tecido social e da organização do trabalho na capital do Império. A presença marcante dessa diversidade constituía um campo fértil para a afirmação de elementos identitários, que ensejavam nas sociedades de mútua ajuda um ambiente por vezes ajustado às manifestações representativas e simbólicas de grupos que compartilhavam determinadas experiências e carregavam consigo certos valores e costumes em comum.

A Sociedade Auxiliadora dos Artistas Alfaiates ao expor seus objetivos, no Capítulo 1, Artigo 1ํㅡㄹ dos seus estatutos, se comprometia a: "Oferecer pensões para herdeiros dos associados, sanar suas enfermidades e civilizar aqueles que exerciam a arte de alfaiate" bem como defender os preceitos de "moralidade, civilização e humanidade para minorar e aliviar os males de seus associados" (CONSULTA SOBRE OS ESTATUTOS DA SOCIEDADE AUXILIADORA DOS ARTISTAS ALFAIATES, 1876). Ao antecipar valores subjetivos aos fins securitários, a entidade reforçava o grau de importância dispensada às representações e valores de comportamento aos quais seus membros deveriam guiar-se. Parecia ser fundamental para os alfaiates elevar certas regras de conduta com o propósito de assegurar uma boa impressão sobre sua profissão e sobre o caráter daquele que a exercia, como ao próprio enaltecimento da agremiação perante a sociedade em geral. No âmbito simbólico, o trabalho adquiria outros emblemas, bem diferentes daquele tom pejorativo e humilhante da atividade braçal do escravo, considerada indigna de uma pessoa livre. Passava agora a ser exemplo 
de moralidade, civilização, união, modernidade, entre outras virtudes amplamente difundidas pelas sociedades por ofícios mecânicos, manuais e liberais espalhadas pela Corte.

Assim, não só ao auxílio e o amparo mútuo artífices de associações como a dos Artistas Alfaiates se dedicavam. Sua missão consistia em algo de maior magnitude, servindo de instrumento de mobilização e dignificação do trabalho, de altruísmo e de nobilitação de suas habilidades. Elas passavam, desta forma, a cumprir um papel pedagógico, professoral, de congregar e guiar os artistas da Corte rumo à insígnia moralizante do labor, como é possível notar também nos estatutos da sociedade Trabalho, União e Moralidade e ao prescrever em seus fins:

Art. $3^{\mathrm{o}}$ Moralizar e instruir pelo exemplo, pelos conselhos, e pela doutrina escrita aos artistas e operários para que tenham no país, a reputação e importância social de que gozão seus irmãos nos países ilustrados.

Art. 4ํㅜ Para complemento de tão justos fins, a associação se esforçará para conseguir que todos os artistas se alistem sob a bandeira social, Trabalho, União e Moralidade (CONSULTA SOBRE OS ESTATUTOS DA ASSOCIAÇÃO NACIONAL DOS ARTISTAS BRASILEIROS TRABALHO, UNIÃO E MORALIDADE, 1862).

Sua missão de guiar os trabalhadores à bandeira da moralidade, da união e do trabalho implicava também fornecer instrução primária e ensino técnico aos filhos órfãos dos artistas empobrecidos. Sendo assim, o Artigo 7º, que ampliava as obrigações da sociedade, previa em seus parágrafos que, tão logo a entidade reunisse condições, construiria uma oficina destinada à instrução dos sócios e seus filhos que desejassem enveredar pelo ofício das artes, como também erguer uma enfermaria para o atendimento dos sócios, disponibilizando um médico para cada freguesia atendida pela associação.

Ainda dentro do campo simbólico, as representações religiosas perdiam cada vez mais espaço nas práticas e nos discursos dos trabalhadores, sobretudo a partir da década de 1850, quando as Irmandades passaram a concorrer com as sociedades de auxílio mútuo nas atividades de amparo social, pelo menos no contexto da capital do Império. Mesmo assim, elas não sucumbiram ao surgimento das mutuais e beneficentes de caráter laicizado; conviviam no mesmo espaço público, sendo possível supor que muitos trabalhadores membros de mutuais pertencessem também a irmandades religiosas. Em se tratando 
dos sapateiros, uma das únicas irmandades ligadas a um ofício em 1870 na Corte era a Irmandade de São Chrispim e São Chrispiniano.

No dia 10 de maio de 1875, na residência do Sr. Manoel Pereira D’Ávila, à rua da Alfandega, 330, região central da cidade, diversos artífices, convidados pelo Sr. Antônio Augusto Botelho, se fizeram presentes em assembleia geral no intuito de instalar uma sociedade de classe representativa de seus interesses "sob a invocação de seu patriarca São Chrispim e São Chrispiniano" para socorrê-los em momentos de indigência. Depois de aprovada a proposta por todos os presentes, seguiu-se a eleição da Diretoria provisória, composta por um presidente e um vice, $1^{\mathrm{O}}$ e $2^{\mathrm{o}}$ secretários, um tesoureiro, um procurador e um Conselho de 12 membros. Assinaram a ata 16 pessoas com seus respectivos endereços residenciais. Constituía-se na Corte a Sociedade de Socorros Mútuos Protetora dos Artistas Sapateiros e Profissões Correlativas.

Semanas depois, concluído os trabalhos de organização da sociedade e formalização de suas leis sociais, encaminharam ao governo o pedido de consulta aos seus estatutos com o objetivo de vê-los aprovados pelas autoridades competentes. Na ocasião, ao interpor parecer sobre o requerimento, Campos de Medeiros, Chefe da 2a Secretaria do Ministério dos Negócios do Império, depois de enumerar dezenas de substitutivos a vários dispositivos dos estatutos, para em seguida encaminhá-lo à Seção dos Negócios do Império do Conselho de Estado, concluía:

A máxima parte destas emendas estão por sua natureza explicadas. Quase todas tendem a definir ou garantir melhor os direitos dos sócios, cercear o desmedido arbítrio das administrações, facilitar as reuniões da assembleia geral dos sócios e suprir certas formalidades substanciais exigidas pela lei (CONSULTA SOBRE OS ESTATUTOS DA SOCIEDADE DE SOCORROS MÚTUOS PROTETORA DOS ARTISTAS SAPATEIROS E PROFISSÕES CORRELATIVAS, 1877).

Com os papéis em mãos, a Seção seguia a mesma rotina burocrática: ratificar a maioria das emendas propostas pela Secretaria, além de propor outras mais. Não obstante, chama a atenção uma discordância dos conselheiros José Pedro Dias de Carvalho, Jeronymo José Teixeira Júnior e Paulino José Soares de Souza em relação ao parecer de Medeiros, permitindo perceber significados que reforçam as experiências em comum de certos segmentos de trabalhadores, à revelia de qualquer esfera legal ou administrativa, a qual cabia ao governo legislar, mas 
essencialmente ligados às antigas manifestações identitárias das corporações de ofício e das Irmandades que ainda se reproduziam. Tratava-se de uma substituição na letra do Art. 23 indicada por Campos de Medeiros, no seguinte teor: "No Art. 23 depois de - posse - diga-se: da mesa da assembleia geral e da Comissão de contas poderá ser em ato contínuo à eleição; a da diretoria, porém, e dos vogais do conselho." Originalmente o artigo prescrevia: "A posse [da diretoria] deverá ter lugar no dia 25 de outubro (Dia de São Chrispim)." Os conselheiros relatores discordaram da alteração proposta pelo secretário, sugerindo que se mantivesse no documento o teor original do artigo: "O Art. 23 deve ficar como está redigido. A sociedade quer lembrar o dia do santo invocado como seu patrono pelos sapateiros porque se lhe há de tolher esta recordação?" (CONSULTA SOBRE OS ESTATUTOS DA SOCIEDADE DE SOCORROS MÚTUOS PROTETORA DOS ARTISTAS SAPATEIROS E PROFISSÕES CORRELATIVAS, 1877).

No campo simbólico, mantinham-se algumas representações das antigas corporações de ofício ou de irmandades ligadas aos ofícios manuais, como homenagens aos santos padroeiros, mesmo que sob outra linguagem, distante do peso religioso, mas não totalmente distanciada deste emblema. Nota-se a importância dada à figura do patrono pelos fundadores da sociedade ao clamarem pela proteção de São Chrispim e São Chrispiniano no ato da criação da associação e na celebração da posse dos novos diretores, não no dia de sua eleição, como queria Campos de Medeiros em sua interposição, mas exatamente na data de comemoração do patrono, como prescrevia o texto original dos estatutos em seu Artigo 23. Apregoava, inclusive, em seu parágrafo único, que e a festividade da posse se realizaria junto com a do santo padroeiro, aclamando a nova diretoria sob seu amparo e proteção.

À medida que novas formas organizativas dos ofícios manuais e operários se desenvolviam, categorias de representação eram constituídas e absorvidas, substituindo tradições seculares, ou ajustando as expressões simbólicas ainda persistentes nas expressões culturais dos trabalhadores.

Como todos os grupos de seres humanos, as coletividades de trabalhadores, quer sejam oficialmente organizadas ou não, ocasionalmente entregaram-se a práticas formalizadas associadas a objetos e símbolos apropriados. [...] é muito curioso que para cada tipo de ofício surja, nos artífices que os exercem, um caráter específico, um temperamento especial. (HOBSBAWM, 2000, p. 99/149) 
Para Hobsbawm, a história apresenta os sapateiros como uma classe propícia à mobilização, organização e militância política em razão de seu temperamento alegre e festivo. Sem deixarmos de considerar as peculiaridades dos contextos históricos, a organização desses profissionais ao longo de todo o século XIX somava-se a outras categorias de ofícios, cujos trabalhadores possivelmente existiam em número mais elevado, tais como alfaiates, marceneiros e carpinteiros, gráficos e trabalhadores da construção civil, por exemplo.

Evidentemente, não se trata de conceber a Sociedade Protetora dos Sapateiros e Profissões Correlativas como uma entidade de resistência ou de mobilização política dos artífices de São Chrispim, reunidos em uma mutual. Nem sequer há indícios dessas práticas na documentação pesquisada ou menções na historiografia que permitam inferências sobre esse tipo de mobilização por parte dos sapateiros na capital do Império. Não é o caso, por exemplo, dos compositores tipográficos, que declararam greve em 1858. O movimento desencadeado pelos tipógrafos, reunidos em sua maioria na Associação Tipográfica Fluminense, fundada na Corte em 1853, registraria um dos primeiros indícios de uma mobilização política voltada para a luta direta contra os abusos dos patrões, com a peculiaridade de ser organizada por uma associação mutualista. (VITORINO, 1999, p. 72). Outrossim, tratase de considerar e constatar a importância das sociedades de mútua ajuda na constituição da cultura associativa dos trabalhadores, cujas experiências podem ser notadas em várias conjunturas históricas, bem como a importância do papel dos ofícios manuais na formação das classes operárias ao longo do século XIX.

\section{Nobilitar as artes e dignificar os artífices}

A imagem da sociedade também estava em jogo e, portanto, a primazia deveria ser a integridade moral de seus membros na defesa do interesse coletivo. Por isso mesmo, para qualquer proposto ser aceito em seu quadro associativo, logo em seu artigo primeiro, a Sociedade de Beneficência 31 de Outubro Amor ao Trabalho estatuía: “[...] será composta de ilimitado número de sócios sem distinção de classes que a ela quiserem pertencer, reconhecida que seja a sua honestidade." (CONSULTA SOBRE OS ESTATUTOS DA SOCIEDADE BENEFICENTE 31 DE OUTUBRO AMOR AO TRABALHO, 1877). Percebe-se o tom da conduta moral extensiva não só ao indivíduo como também à sua classe, salvo as ambiguidades que o termo pudesse sugerir. 
No campo da linguagem, o que se observa dos elementos da cultura entre os trabalhadores deriva do próprio processo de democratização verificado nas mutuais de ofício ou categoria profissional se contrastadas com as antigas corporações de ofício. Elas se tornam nitidamente mais abertas e sem o rigor estrito das hierarquias laborais, contribuindo para a ampliação das experiências coletivas dos trabalhadores. Desta forma, os artífices e suas redes horizontais de sociabilidade exclamam uma maneira de ampliar sua participação política e sua integração no tecido social, como é possível perceber nas dinâmicas associativas contempladas neste texto. Ao passo que as transformações ocorridas nas relações de produção traziam consigo incrementos na tecnologia do trabalho, redefinindo o campo das técnicas e habilidades profissionais, os espaços de sociabilidade relacionados às artes e aos ofícios se pluralizavam. Com isso, sua natureza fechada esmaece à medida que as associações de auxílio mútuo e, mais tarde, os sindicatos adquirem um perfil mais aberto em relação aos níveis de qualificação profissional exigidos, permitindo figurar entre seus sócios uma gama diversificada de talentos.

O mutualismo entre os trabalhadores não se restringia, portanto, somente a um fim em si mesmo, ou seja, à sua natureza exclusivamente assistencial. Poderia traduzir também instrumentos de ação autônoma dos trabalhadores e de defesa de outros interesses, ora muito próxima à prática sindical, ora disposta a perpetuar ritos das antigas corporações de ofício e irmandades: formas imbricadas de continuidade e ruptura no interior de organizações comuns às diversas categorias de trabalhadores a partir da segunda metade dos oitocentos, forjadas no interior das sociedades de auxílio mútuo (BATALHA, 1999). As mudanças e permanências das formas associativas entre os trabalhadores ao longo do século XIX, sobretudo em seu perfil, partem, destarte, de uma postura mais fechada para uma posição mais aberta à incorporação de variados segmentos de trabalhadores, embora discriminadamente, identificados com a profissão ou profissões filiadas à associação pretendida.

A ampliação dos espaços de sociabilidade dos trabalhadores dentro das sociedades de categorias profissionais poderia também suscitar desconfianças com relação aos modos de mobilização e atividades relacionadas às práticas sindicais, proibidas pela legislação imperial. A própria experiência da associação de tipógrafos servia como exemplo. A suspeita dos conselheiros da existência de propósitos sindicais em certas associações, a partir do exame dos pedidos de aprovação ou reforma de seus estatutos, poderia motivar a sua reprovação caso percebessem 
objetivos outros, alheios aos fins aos quais se credenciavam: o auxílio mútuo e/ou a beneficência. Mesmo não havendo um universo documental suficiente para decifrar as práticas internas dessas sociedades, a preocupação dos conselheiros de Estado com determinadas atividades relativas ao âmbito do corporativismo profissional e do sindicalismo, manifesta em seus pareceres, acusa a possibilidade de que essas ações fossem difundidas em seu interior. Para Batalha,

[...] existem diversos exemplos de sociedades de socorros mútuos de trabalhadores, que não restringem sua atuação à prestação de auxílios. Se sociedades como a Liga Operária não chegam a constituir casos típicos, na maioria das sociedades de trabalhadores, atividades como a formação profissional, a educação tradicional, a busca de colocação dos associados no mercado de trabalho, são indícios de que a adoção do auxílio mútuo constituem, em grande medida, a fórmula encontrada pelos ofícios para constituírem organizações legais. (BATALHA, 1999, p. 56)

A excepcionalidade da Liga Operária, fundada na Corte em 1870, consistia em agregar às suas atividades fins mais dilatados que extrapolavam o campo meramente securitário. Segundo o autor, além de defender o aumento dos salários e a redução da jornada de trabalho, a associação instituía um tipo de organização interna aos moldes das futuras federações operárias, através de representações por ofício que se encontrasse inscrito na Liga. Quanto a esse modelo organizacional, o capítulo $7^{\circ}$ dos estatutos, denominado "Das Classes Operárias", estipulava:

Art. 29. Cada classe de operários será dirigida por uma Diretoria, composta de um Presidente que fará parte de uma Diretoria Central e de dois Deputados. Estes últimos reunidos aos de todas as outras classes, constituirão a Assembleia Geral da Associação. Não poderá constituir classe um número inferior a 10 membros de cada profissão; neste caso se reunirá a outra classe mais semelhante, podendo desligar-se dela desde que contenha o número acima previsto (CONSULTA SOBRE OS ESTATUTOS DA ASSOCIAÇÃO DE SOCORROS MÚTUOS LIGA OPERÁRIA, 1872).

Esta disposição da assembleia geral, em sessão que seria formalizada pela presença da maioria dos deputados das classes operárias, e não do conjunto dos sócios, foi considerada pelos conselheiros de Estado como 
um tipo de "organização aristocrática", porém admissível, conquanto aprovada pela maioria dos sócios reunidos em assembleia. Mesmo que figurasse como um modelo sindical, a sua aprovação por parte do governo com a publicação do Decreto $n^{\circ} 5.353$, de 23 de julho de 1873 , não permite compreender suficientemente o quanto determinadas práticas sindicais no interior das mutuais poderiam ser de fato censuradas. A greve dos tipógrafos em 1858, na qual a Associação Tipográfica Fluminense esteve envolvida, não resultou em seu fechamento ou nenhuma outra punição por parte do governo por descumprir a lei e por se envolver em atividades que não condiziam aos seus fins.

As fontes também não permitem afirmar se eles próprios, tanto os fundadores e demais sócios da Liga como os conselheiros de Estado, percebiam tal organização como um modelo constituído aos moldes de uma federação operária. Fato é que a divisão em classes de operários de acordo com sua profissão poderia facilitar a própria administração e representação dos interesses das diversas categorias profissionais presentes na sociedade, formadas pela "reunião de todos os operários e artistas, nacionais e estrangeiros", conforme anunciava o artigo primeiro de seus estatutos. E não perecia ser pouco o número de integrantes da Liga Operária, tomando por base os associados presentes nas duas assembleias gerais para deliberar a respeito das leis sociais da entidade e encaminhar ao governo o pedido de aprovação de seus estatutos.

No dia 10 de março de 1872, cerca de 800 sócios, de um montante de 1.500 inscritos para participar da assembleia geral da Liga Operária, se reuniram no salão do Teatro D. Pedro II para tratar de assuntos relativos à avaliação dos capítulos e artigos do projeto dos estatutos da entidade. A sessão foi encerrada às 15 horas e retomada no dia 17 do mesmo mês às 7 horas da manhã, contando agora com 900 presentes, no mesmo local da primeira assembleia. Percebe-se um número considerável de membros presentes nas duas reuniões, permitindo inferir que a organização por representatividade de classes profissionais poderia facilitar o encaminhamento de demandas concernentes aos seus interesses especificamente. Ademais, os propósitos da Liga não se restringiam aos socorros, almejando também o "auxílio moral" de que pudesse dispor, além de "procurar, por todos os meios ao seu alcance, melhorar a sorte das classes operárias, introduzindo melhoramentos em todos os ramos do trabalho artístico e industrial" (CONSULTA SOBRE OS ESTATUTOS DA ASSOCIAÇÃO DE SOCORROS MÚTUOS LIGA OPERÁRIA, 1872), inclusive com investimentos na instrução de seus membros. 
O ensino primário e o técnico em muitos casos compunham os regimentos das entidades, como é possível identificar no parágrafo $3^{\circ}$ do Artigo $2^{\mathrm{o}}$ dos estatutos da Liga Operária: "Propagar a instrução, como o meio mais eficaz de esclarecer quer o operário, quer o artista, tanto na invenção, como na prática do trabalho manual." Princípio que despertou a atenção do conselheiro relator ao ratificar sua condição de entidade de socorros mútuos, e não de beneficência, pois se destinava não só a socorrer os sócios, como também a melhorar sua instrução, os trabalhos artísticos e industriais. Além disso, a Liga incumbia os sócios-diretores de doar cada qual um livro para a biblioteca da agremiação, tão logo tomassem posse em seus cargos, no intuito de "criar uma biblioteca com os recursos de que trata o art. $5^{\circ} \S 3^{\circ}$, e com aqueles de que puder usar em bem da Associação". E a Diretoria Central de "trabalhar por todos os meios a seu alcance, e dentro das forças da Associação, para criar aulas, onde os associados se possam instruir" (CONSULTA SOBRE OS ESTATUTOS DA ASSOCIAÇÃO DE SOCORROS MÚTUOS LIGA OPERÁRIA, 1872).

Com a demora em ver aprovadas suas leis orgânicas, a Diretoria da Liga enviou, em 16 de novembro de 1872, um requerimento ao governo pedindo maiores informações sobre o andamento do processo de legalização da associação, visto que, após a solução das pendências indicadas pela Seção dos Negócios, de nada mais haviam sido informados seus signatários. Uma das justificativas do apelo era que, sem o seu reconhecimento como sociedade anônima pelo governo, não poderiam ministrar aulas noturnas aos associados, tampouco aplicar os recursos financeiros obtidos pelos depósitos aplicados pelos sócios.

\section{Enaltecer a condição intelectual e habilitar pela instrução}

A preocupação em instruir os trabalhadores não era uma exclusividade das sociedades de mútua ajuda espalhadas pelo país, muito menos da Corte. Tratava-se de um fator da cultura associativa entre trabalhadores. Instruir significava elevar a condição intelectual do operário ou artífice, implicava caracterizar o trabalhador especializado, distinguido pela técnica e habilitado ao ofício. Portanto, as associações cumpriam o papel da nobilitação do ofício para diferenciar o artífice qualificado daquele considerado um intruso, aventureiro, sem preparo para as artes manuais dentro do mercado de trabalho. O próprio sucesso e reconhecimento da associação relacionava-se à sua capacidade de arregimentar em seu seio membros de reconhecida qualificação e, 
ao mesmo tempo, representar um lugar de valorização de seu ofício, preservação de sua identidade e defesa de seus interesses.

Ainda a respeito da prerrogativa de subsidiar a formação e crescimento intelectual e técnico de seus associados e dependentes, a Associação Nacional dos Artistas Brasileiros Trabalho, União e Moralidade se comprometia a "mandar a Europa de três e três anos, um dos artistas associados ou filhos destes, para aperfeiçoar-se na arte ou ofício de sua escolha, a qual será na sua volta, mestre e diretor da respectiva oficina da associação" (CONSULTA SOBRE OS ESTATUTOS DA ASSOCIAÇÃO NACIONAL DOS ARTISTAS BRASILEIROS TRABALHO, UNIÃO E MORALIDADE, 1862). Contudo, pela ótica do conselheiro relator Bernardo de Souza Franco, agregar tantas funções em uma sociedade de socorros mútuos desviava o sentido de sua existência, além de sacrificar os cofres da entidade com demandas não condizentes aos seus fins. Assegurava, entretanto, não se tratar de uma investida do governo contra a organização de sociedades de classe, e sim de ressaltar a importância de tais agremiações para os trabalhadores. Pelo menos na ordem do discurso, tais alegações ganhavam respaldo.

São merecedoras de animação as Sociedades de Socorros mútuos de artistas, e já, entre outras, estão aprovadas na Corte do Império as de que tratam os Decretos no. 2753 e no. 2759; e não menos os são as que tendam a promover o desenvolvimento das artes, e bom gosto de suas obras; são elas porém de difícil direção quando abraçam ao mesmo tempo ramos ou objetos diretos como socorros aos artistas e as suas famílias, prestadas em moeda, com o estabelecimento de oficinas, de hospitais, de pensões para viagens. Reúnem-se assim fins diversos, e complicados, que exigem condições especiais de organização, direção, e fiscalização, aos quais faltando não podem desenvolver seus fins (CONSULTA SOBRE OS ESTATUTOS DA ASSOCIAÇÃO NACIONAL DOS ARTISTAS BRASILEIROS TRABALHO, UNIÃO E MORALIDADE, 1862). ${ }^{3}$

Para o conselheiro, transferir recursos provenientes da arrecadação de todos os sócios para beneficiar os filhos de alguns com viagens dispendiosas à Europa consistia num ato injusto, ou seja, de privilegiar

\footnotetext{
3 Os decretos a que se refere o conselheiro relator na citação tratam-se da aprovação dos Estatutos da Sociedade Beneficente dos Artistas do Arsenal da Marinha, Decreto 2.753 de 23 de fevereiro de 1861, e da Sociedade Filantropia dos Artistas, Decreto 2.759 de 9 de março de 1861.
} 
uns poucos por conta dos esforços de muitos trabalhadores que ansiavam, com suas sofridas contribuições ao caixa da entidade, poder contar com ela em momentos de necessidade. Isso parecia ter sentido na visão dos conselheiros. Por outro lado, no entendimento da associação, os trabalhadores filiados teriam a possibilidade de se aproximar das experiências vivenciadas pelos artífices europeus, para o enaltecimento dos ofícios e das artes praticadas pelos artistas brasileiros.

Tais interesses tencionavam favorecer a existência de um espaço de sociabilidade adequado ao convívio e à troca de experiências entre aprendizes brasileiros na afirmação de suas identidades através da absorção de valores da cultura laboral de trabalhadores europeus. Parece que não era suficiente compartilhar essas experiências com os artistas imigrantes presentes na Corte ou até mesmo fortalecer as trocas entre as diversas sociedades. Paradoxalmente, os conselheiros chamavam a atenção dos signatários da sociedade por não permitir a admissão de trabalhadores imigrantes e libertos nos estatutos da entidade, cujas cláusulas nesse sentido deveriam ser prontamente eliminadas. Criticavam a postura da entidade em não conceber escravos como operários - mesmo que pela lei não pudessem se associar - combinada com a exclusão dos operários estrangeiros da possibilidade de filiaremse à sociedade. No entendimento do relator, não se ajustava à natureza associativa de trabalhadores, criar obstáculos à filiação de outras nacionalidades ou até mesmo de artistas negros.

A solidariedade entre os artistas estaria circunscrita aos brasileiros brancos e/ou pardos, sem considerar a possibilidade de ingresso de negros e imigrantes. Desse modo, a censura à identidade operária do escravo, que não tinha o direito de associar-se em agremiações civis, com exceção das confrarias e irmandades, pode ser interpretada como uma forma velada de impedir o ingresso de "homens de cor" na sociedade. Isso em decorrência de discriminações étnicas e raciais, mas também pode ser interpretado como uma forma de defesa do trabalhador brasileiro livre perante a concorrência do mercado de trabalho. Escravos encontravam-se empregados em vários ofícios na praça carioca, concorrendo com trabalhadores livres com o incremento cada vez mais acentuado de artistas e operários estrangeiros. Assim, para valorizar a figura do trabalhador brasileiro, muitas eram as iniciativas que a sociedade pretendia colocar em curso na intenção declarada de projetar o artista nacional. Pretensão essa frustrada pelos conselheiros relatores da Seção dos Negócios do Império do Conselho de Estado, ao não aprovarem os seus estatutos. 


\section{Considerações finais}

As mutuais e beneficentes de trabalhadores abrangiam categorias profissionais dos mais variados ofícios, tais como alfaiates, barbeiros, sapateiros, maquinistas, artífices, professores, além de servidores públicos, empregados do comércio e outros serviços. Muitos trabalhadores, no esforço de valorizar sua profissão face à natureza depreciativa que a escravidão conferia ao trabalhador braçal, eram capazes de forjar culturas associativas entre si, no intuito de fortalecer vínculos e criar uma identidade positiva perante a sociedade. Frente ao impedimento de outras formas associativas comuns à cultura operária, os trabalhadores recorriam às sociedades de socorros mútuos como modelo mais ajustado de organização coletiva para estabelecer vínculos de solidariedade, garantir seus interesses no mercado de trabalho e ratificar a importância de seu ofício, das artes mecânicas e liberais.

A valorização do trabalho e das representações simbólicas do universo laboral é presenciada de forma considerável nos estatutos das sociedades de ofícios ou categorias profissionais, sempre louvadas pelos signatários das elites políticas da Corte, neste caso específico, os conselheiros da Seção dos Negócios do Império do Conselho de Estado. Esse discurso, longe de produzir uma ideologia de luta de classes, de rivalidades existentes entre o patrão e o empregado e da resistência à exploração do capital, defendia o conceito de um trabalhador e de seu ofício voltados a promover e valorizar a dignidade, o altruísmo e a moralidade.

Em se considerando a importância do papel dos artífices no campo das relações políticas vigentes na segunda metade do século XIX, os interesses em jogo variavam e projetavam deslocamentos distintos dentro de um mesmo propósito: adquirir reconhecimento social e político no espaço público por via de estratégias privadas de público interesse, nesse caso, a proteção social.

\section{Referências}

BATALHA, Cláudio. Identidade da classe operária no Brasil (1880-1920): atipicidade ou legitimidade. Revista Brasileira de História, São Paulo, v. 12, n. 23/24, p. 111-124, set. 1991-ago. 1992.

. Sociedades de trabalhadores no Rio de Janeiro do século XIX: algumas reflexões em torno da classe operária. Cadernos AEL, Campinas, v. 6, n. 10/11, p. 41-68, 1999.

. Cultua associativa do Rio de Janeiro da Primeira República. In: BATALHA, Cláudio H. M.; SILVA, Fernando Teixeira da; FORTES, Alexandre (Org.). Culturas 
de classe: identidade e diversidade na formação do operariado. Campinas: Unicamp, 2004. p. 95-119.

CADERNOS AEL. Campinas, v. 6, n. 10/11, 1999.

FONSECA, Vitor M. M. da. No gozo dos direitos civis: associativismo no Rio de Janeiro, 1903-1916. Rio de Janeiro: Muiraquitã, 2008.

FORTES, Alexandre. Da solidariedade a assistência: estratégias organizativas e mutualidade no movimento operário de Porto Alegre na primeira metade do século XX. Cadernos AEL, Campinas, v. 6, n. 10/11, p. 171-218, 1999.

JESUS, Ronaldo Pereira de. Visões da Monarquia: Escravos, Operários e Abolicionistas na Corte. Belo Horizonte: Argvmentvm, 2009.

JESUS, Ronaldo Pereira de; LACERDA, David. Dinâmica associativa no século XIX: socorro mútuo e solidariedade entre livres e libertos no Rio de Janeiro Imperial. Revista Mundos do Trabalho. Florianópolis, v. 2, n. 4, p. 126-142, ago.-dez. 2010. Disponível em: <www. periodicos.ufsc.br/index.php/mundosdotrabalho>. Acesso em: 03 mar. 2011.

HOBSBAWM, Eric J. Mundos do Trabalho: novos estudos sobre história operária. São Paulo: Paz e Terra, 2000.

LACERDA, David P. Solidariedade entre oficios: a experiência mutualista no Rio de Janeiro imperial (1860-1882). 2011. Dissertação (Mestrado em História Social) Universidade Estadual de Campinas (UNICAMP), Campinas, 2011.

MAC CORD, Marcelo. Andaimes, Casacas, Tijolos e Livros: uma associação de artífices no Recife, 1836-1880. 2009. Tese (Doutorado em História Social) - Universidade Estadual de Campinas (UNICAMP), Campinas, 2009.

MAC CORD, Marcelo; BATALHA, Cláudio H. (Org.). Organizar e proteger: Trabalhadores, associações e mutualismo no Brasil (séculos XIX e XX). Campinas: Unicamp, 2014.

NOMELINI, Paula Christina. Associações operárias mutualistas e recreativas em Campinas (1906-1931). 2007. Dissertação (Mestrado em História) - Universidade Estadual de Campinas (UNICAMP), Campinas, 2007.

SILVA Jr., Adhemar Lourenço da. As sociedades de socorros mútuos: estratégias privadas e públicas (estudo centrado no Rio Grande do Sul - Brasil, 1854-1940). 2004. Tese (Doutorado) - Pontifícia Universidade Católica do Rio Grande do Sul (PUCRS), Porto Alegre, 2004.

VITORINO, Arthur José Renda. Escravismo, proletários e a greve dos compositores de 1858 no Rio de Janeiro. Cadernos AEL, Campinas, v. 6, n. 10/11, p. 69-108, 1999.

\section{Fontes}

BRASIL. Almanak Administrativo, Mercantil e Industrial do Rio de Janeiro. Rio de Janeiro: Typografia Universal Laemmert, 1844-1888. Disponível em: <http://wwwapps.crl.edu/brazil/almanak>. Acesso em: 16 ago. 2010.

BRASIL. Colecção das Leis do Império do Brasil. Rio de Janeiro: Typografia Nacional, 1860-1882. Disponível em: <http://www2.camara.leg.br/atividade-legislativa/ legislacao/publicacoes/doimperio>. Acesso em: 11 jan. 2011.

BRASIL. Fundo da Seção de Negócios do Conselho de Estado, 1860-1882. Ministério da Justiça. Arquivo Nacional. Rio de Janeiro, Sistema de Gestão de Documentos de Arquivos - SIGA. 
CONSULTA SOBRE OS ESTATUTOS DA SOCIEDADE BENEFICENTE 31 DE OUTUBRO AMOR AO TRABALHO. 18 de setembro de 1877. Conselho de Estado do Império do Brasil. Seção dos Negócios do Império. Cf.: BRASIL. Ministério da Justiça. Arquivo Nacional. Caixa 555, pac. 2, env. 1, doc. 18. Rio de Janeiro, Sistema de Gestão de Documentos de Arquivos - SIGA.

CONSULTA SOBRE OS ESTATUTOS DAASSOCIAÇÃO DE SOCORROS MÚTUOS LIGA OPERÁRIA. 28 de junho de 1872. Conselho de Estado do Império do Brasil. Seção dos Negócios do Império. Cf.: BRASIL. Ministério da Justiça. Arquivo Nacional. Caixa 551, pac. 1, env. 1, doc. 8. Rio de Janeiro, Sistema de Gestão de Documentos de Arquivos - SIGA.

CONSULTA SOBRE OS ESTATUTOS DA ASSOCIAÇÃO NACIONAL DOS ARTISTAS BRASILEIROS TRABALHO, UNIÃO E MORALIDADE. 22 de setembro de 1862. Conselho de Estado do Império do Brasil. Seção dos Negócios do Império. Cf.: BRASIL. Ministério da Justiça. Arquivo Nacional. Caixa 532, pac. 1, env. 5, doc. 25. Rio de Janeiro, Sistema de Gestão de Documentos de Arquivos - SIGA.

CONSULTA SOBRE OS ESTATUTOS DA SOCIEDADE AUXILIADORA DOS ARTISTAS ALFAIATES. 18 de julho de 1876. Conselho de Estado do Império do Brasil. Seção dos Negócios do Império. Cf.: BRASIL. Ministério da Justiça. Arquivo Nacional. Caixa 554, pac. 1, env. 3, doc. 11. Rio de Janeiro, Sistema de Gestão de Documentos de Arquivos - SIGA.

CONSULTA SOBRE OS ESTATUTOS DA SOCIEDADE DE SOCORROS MÚTUOS PROTETORA DOS ARTISTAS SAPATEIROS E PROFISSÕES CORRELATIVAS. 13 de abril de 1877. Conselho de Estado do Império do Brasil. Seção dos Negócios do Império. Cf.: BRASIL. Ministério da Justiça. Arquivo Nacional. Caixa 555, pac. 1, env. 2, doc. 9. Rio de Janeiro, Sistema de Gestão de Documentos de Arquivos - SIGA.

ESTATUTOS DA SOCIEDADE BENEFICENTE DOS ARTISTAS DO ARSENAL DA MARINHA. Decreto 2.753 de 23 de fevereiro de 1861. BRASIL. Colecção das Leis do Império. Tomo XXIV, Parte II. Rio de Janeiro: Tipografia Nacional, 1861. Disponível em: <http://www.camara.gov.br/Internet/InfDoc/conteudo/colecoes/Legislacao/ leis1861/indice2.pdf>. Acesso em: 17 dez. 2013.

ESTATUTOS DA SOCIEDADE FILANTROPIA DOS ARTISTAS. Decreto 2.759 de 9 de março de 1861. BRASIL. Colecção das Leis do Império. Tomo XXIV, Parte II. Rio de Janeiro: Tipografia Nacional, 1861. Disponível em: <http://www.camara.gov. br/Internet/InfDoc/conteudo/colecoes/Legislacao/leis1861/indice2.pdf >. Acesso em: 17 dez. 2013. 